nevertheless, to show a real connexion between maternal steroid levels and the onset of labour.

We thank our colleagues in the maternity hospital for allowing us access to their patients. Dr. George Wilson instituted the assay methods which we used and $\mathrm{Mr}$. Duncan Bruce supervised the radioimmunoassays. The work was done during the tenure of a Ford Foundation Scholarship to one of us (M.S.).

\section{References}

Csapo A. I. (1969). In Ciba Foundation Study Group No. 34, Progesterone: Its Regulatory Effect on the Myometrium, ed G. W. E. Wolstenholme and J. Knight. London, Churchill.
Csapo, A. I., Pohanka, O., and Kaihola, H. (1974). British Medical fournal, $1,137$.

Currie, W. B., et al. (1973). In Endocrine Factors in Labour, ed. A. Klopper, and J. Gardner. Cambridge, Cambridge University Press.

Hotchkiss, I., Atkinson, L. E., and Knobil, E. (1971). Endocrinology, 89, 177. Johansson, E. D. B. (1969). Acta Endocrinologica, 61, 592. Johansson, E. D. B. (1969). Acta Endocrinologica, 61, 592.
Klopper, A. (1969). In The Ednocrinology of Pregnancy, ed. F. Fuchs, and
A. Klopper. New York, Harper and Row.

Klopper, A. (1973). In Endocrine Factors in Labour, ed. A Klopper and J. Gardner. Cambridge, Cambridge Univeristy Press.

Liggins, G. C. (1973 a). Clinical Obstetrics and Gynecology, 16, (3) 148.

Liggins, G. C. (1973 b). In Endocrine Factors in Labour, ed. A. Klopper and J. Gardner. Cambridge, Cambridge University Press.

Pinto, R. M., et al. (1964). American fournal of Obstetrics and Gynecology, 88,759 .

Shaaban, M. M., and Klopper, A. (1973). Fournal of Obstetrics and Gynaecology of the British Commonwealth, 80, 210.

Turnbull, A. C., et al. (1974). Lancet, 1, 101.

Wilson, G. R. (1973). Clinica Chimica Acta, 46, 297.

\title{
Role of Gastric Irradiation in Management of Peptic Ulceration and Oesophagitis
}

\author{
J. M. FINDLAY, G. A. NEWAISHY, W. SIRCUS, J. P. A. MCMANUS
}

British Medical fournal, 1974, 3, 769-771

\section{Patients and Methods}

\section{Summary}

Twenty-four patients with peptic oesophagitis or ulceration of the stomach or duodenum have been treated with irradiation of the stomach. They were selected on the grounds of their unsuitability for surgery because of associated medical conditions or because of failure of repeated gastric surgery. Twenty of the patients $(83 \%)$ were 60 years of age or over. Of those treated $19(79 \%)$ obtained complete symptomatic relief. Endoscopic improvement occurred in most cases. Acid reduction to an average of $30 \%$ of the pretreatment levels was noted at 11 months and $\mathbf{5 8} \%$ at 30 months. No morbidity was observed attributable to the irradiation.

\section{Introduction}

There is a natural reluctance on the part of surgeons to operate on the elderly. This sentiment is reinforced by the frequent presence of associated illnesses. When conventional treatment, medical or surgical, has failed and the patient is left with lesions hazardous to life or producing distressing symptoms pressure can be brought to bear to embark on surgery even though it carries with it the risk of significant mortality and morbidity. Surgery in this group is a calculated investment in the future, when the duration and quality of life cannot be assured. Other forms of conservative therapy, therefore, are to be welcomed but require critical evaluation.

We describe our experience of gastric irradiation in such an "at-risk" group of 24 patients with peptic ulceration and oesophagitis.

Gastrointestinal Unit, Western General Hospital, Edinburgh EH4 2XU

J. M. FINDLAY, M.R.C.P., D.M.R.D., Senior Registrar

W. SIRCUS, M.D., F.R.C.P., Consultant Physician

J. P. A. MCMANÜS, M.B., F.R.C.P., Consultant Physician

South Eastern Region Radiotherapy Service, Royal Infirmary and Western General Hospital, Edinburgh

G. A. NEWAISHY, M.B., F.F.R., Consultant Radiotherapist

Since 1955 selected patients in this unit have been treated with gastric radiotherapy though in recent years its use has been increasing. During this period 24 patients have received such treatment, most of whom were over 60 years of age (table I). Their presenting symptoms were often multiple and consisted of dysphagia (11 cases), heartburn (8), epigastric pain (8), backache (1), and bleeding (7).

TABle I-Age Distribution of the 24 Patients Treated with Gastric Irradiation \begin{tabular}{ll|c|c|c|c|c|c|c}
\hline Age in years &. & $21-30$ & $31-40$ & $41-50$ & $51-60$ & $61-70$ & $71-80$ & $81-90$ \\
No. of patients & $\because$ & 1 & 1 & 1 & 3 & 8 & 8 & 2 \\
\hline
\end{tabular}

The 32 lesions finally treated were oesophagitis (15 cases), oesophageal stricture (4), oesophageal ulcers (2), duodenal ulcers (4), jejunal ulcers (3), gastric ulcers (3), and a second-part duodenal ulcer (1). Altogether there were 45 associated conditions (table II).

TABLE II-Associated Conditions (Total 45) Present in 24 Patients Treated with Gastric Irradiation

\begin{tabular}{|c|c|c|c|c|c|}
\hline \multirow[b]{2}{*}{ Alcoholism .. } & & & $\begin{array}{c}\text { No. of } \\
\text { Cases }\end{array}$ & \multicolumn{2}{|r|}{$\begin{array}{l}\text { No. of. } \\
\text { Cases }\end{array}$} \\
\hline & & & .. 1 & Sociopathic personality disord & \\
\hline Cerebral ather & & . & .. & Previous surgery & 3 \\
\hline Chronic bronc & & $\cdots$ & .. & Prostatic hypertrophy. .. & .. \\
\hline Depression .. & & & . & Pulmonary hypertension & .. \\
\hline Generalized at & oscleros & & 1 & Pulmonary tuberculosis & . \\
\hline Gout $\quad \ldots$ & 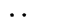 & & . & Pneumonectomy & .. \\
\hline Hypertension. & & & . & Renal Failure ... & .. \\
\hline Kyphoscoliosi & . & & .. & Respiratory failure & .. \\
\hline Lymphatic leu & $\operatorname{mia}(\mathrm{ch}$ & ronic) & . & Rheumatoid arthritis .. & . \\
\hline Myocardial is & $\mathrm{mia}$ & & . & Sïgren's syndrome & . \\
\hline Myxoedema* & $\cdots$ & .. & .. & Thyrotoxicosis (active)* & .. \\
\hline & t & .. & .. & Ulcerative colitis $\quad \ldots$ & .. \\
\hline Osteoarthrosis & .. & . & . & Zollinger-Ellison syndrome & . \\
\hline Osteoporosis & & . & .. & & \\
\hline
\end{tabular}

*On treatment.

In addition to careful history taking and clinical examination the diagnosis was established by barium-meal examination and in most cases upper gastrointestinal endoscopy. Only patients referred on account of significant persistent symptoms were considered eligible for therapy, and this implied that they had been regarded as unsuitable for elective gastric surgery because 
of their age or general condition or the presence of a serious complicating associated disorder-for example, severe ischaemic heart disease or advanced obstructive airways disease. Acid secretion studies were carried out to determine the "maximal" acid response to histamine and, since 1966, pentagastrin. Follow-up endoscopy was performed at intervals to determine the response to treatment. Secretion studies when feasible were also carried out at intervals. Studies of the fasting serum gastrin levels as well as of the effect of irradiation on the gastric mucosa were conducted and will be reported elsewhere.

Method of Irradiation.-The stomach was localized, after screening with barium, in the position in which therapy would be given. A metal marker was applied to the anterior abdominal wall to represent the centre of the treatment field. Opposed anterior and posterior fields were used. The $6-\mathrm{meV}$ treatment machine could swing through $180^{\circ}$ to treat the posterior field. Generous fields were selected to allow for movement of the stomach, no attempt being made to treat simply the acid-secreting areas. The doses used initially were below 1,500 rads and varied between 650 and 900 rads. Later the dose was standardized to 1,500 rads given as two five-day courses of 150 rads daily, the courses being separated by two days. Patients given second courses of radiotherapy received up to 1,500 rads. The renal areas were not shielded as this would also shield the stomach. The spinal cord was not shielded as the "dose-time" used was not thought to be detrimental.

\section{Results}

The response to radiotherapy was assessed clinically by endoscopy and secretion studies at regular intervals during follow-up.

\section{SYMPTOMATIC RESPONSE}

The response to therapy in the 24 patients is summarized in the chart.

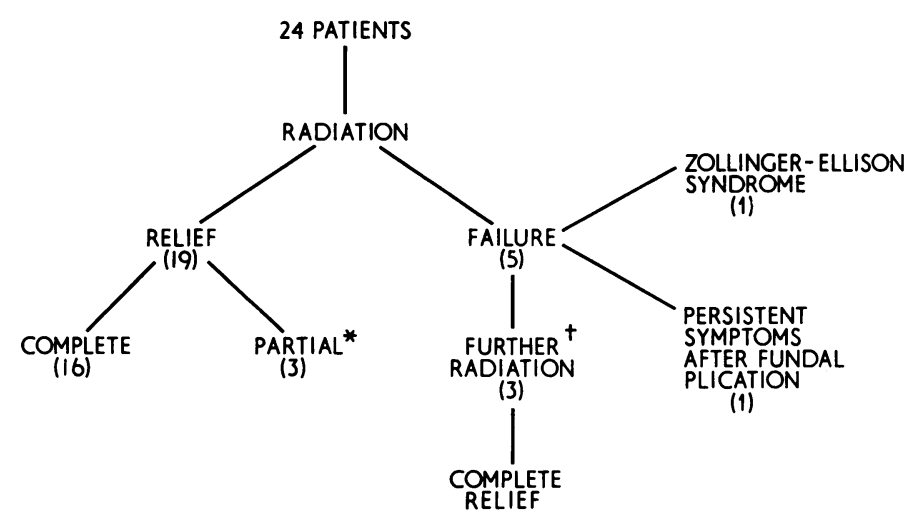

Effect of therapy in 24 patients treated with gastric irradiation.

* Residual mild inflammation at endoscopy.

†Further gastric irradiation at increased dosage.

Complete symptomatic relief was defined as sustained relief of all symptoms without further recourse to or need for antacid therapy.

Partial symptomatic relief was defined as relief of one or more but not all of the dyspeptic symptoms of which the patient complained.

Failure was defined as either no relief or a recurrence of symptoms during the period of follow-up.

Sixteen patients had complete symptomatic relief after a single course of therapy. Three patients had partial symptomatic relief. Treatment failed in five patients, three of whom had further courses of irradiation in increased dosage and ultimately achieved full symptomatic relief.

\section{ENDOSCOPIC ASSESSMENT AND SYMPTOMATIC RELIEF}

Twenty-two patients were examined. Complete healing was seen in 13 patients who obtained full relief of symptoms after a single course of therapy. A further six patients showed evidence of improvement but not complete healing after a single dose of therapy; three of these patients had partial and three complete symptomatic relief. Two patients showed no sustained symptomatic or endoscopic improvement after therapy. In all but one case there was a close correlation between endoscopic appearance and symptomatic improvement, the exception being a patient with severe oesophagitis who obtained complete symptomatic relief without endoscopic change.

\section{SECRETION STUDIES}

The maximum reduction in acid output after treatment in the group as a whole showed a mean fall to $30 \%$ of the pretreatment value. This reduction varied widely between individual cases (range $0-99 \%$ ) and was reached at varying periods after therapy, the mean being 10.7 months (range 0.5-204 months.)

Maximum acid output was last measured at a mean of 30 months after radiotherapy (range 4-204 months); at that time the mean output was reduced to $58 \%$ of the preirradiation value (range $0-110 \%$ ), suggesting a slow rise of acid secretion in the months after irradiation.

\section{MORTALITY}

Six patients died during the period of observation, two from septicaemia, two from bronchopneumonia, one from respiratory failure, and one from bronchogenic carcinoma. The time of death ranged from three months to seven years after irradiation. No patient developed gastric neoplasm in the period of follow-up.

\section{Discussion}

Bassler (1908) first suggested radiotherapy as a means of lowering acid secretion in the treatment of peptic ulceration, and since the first clinical report (Bruegel, 1917) there have been several extensive reviews of its effectiveness as an adjunct to management (Kruglikowa et al., 1936; Hedfeld, 1948; Ricketts et al., 1948; Levin et al., 1954, 1957). Initial reports (Levin et al., 1954, 1957) did not suggest that there were any long-term ill effects. Irradiation nephritis has recently been reported (Thompson et al., 1971) to occur in $37 \%$ of patients at intervals of eight to 19 years after moderate doses (2,000 rads) of irradiation.

Our patients were mostly elderly and all had other serious diseases. In such patients surgery is possibly hazardous, prone to complications, distressing, and often unacceptable to the patient. Age and intercurrent disease may contribute to the disappointing surgical results (Griffiths, 1972). Such patients may derive much benefit from gastric irradiation. The technique is simple, safe, and not associated with complications. Griffiths (1972) studied the consequences of elective gastric surgery for peptic ulcer disease in the over-70s and found a $16 \%$ mortality and an $85 \%$ postoperative complication rate. Moreover, the patients had been regarded as fit for surgery; this was not the case in most of our patients. It is likely that the unusually low $(6 \%)$ operative mortality in the 422 patients over 60 undergoing gastric surgery (elective and emergency) in our unit between 1955 and 1972 was contributed to by our use of radiotherapy.

No patient experienced irradiation sickness or aggravation of the presenting symptoms after treatment. In recent years patients living close to the hospital have received their irradiation on an outpatient basis.

The mean reduction in acid output to $30 \%$ of the preirradiation level at 10.7 months, with a $58 \%$ reduction at 30 months, is similar to the observations of other workers and is in keeping with the therapeutic response previously observed (Klein and) 
Berman, 1961; Brown et al., 1962; Clayman et al., 1968). The response appears unpredictable. The lowering of acid secretion achieved by irradiation gives the underlying lesion an opportunity to heal, and it may be that once healed a lesion is less likely to recur.

The clinical status that led our patients to radiotherapy precluded extensive follow-up; indeed, the select nature of the series and the poor health of the patients is reflected in the $25 \%$ mortality. We do not recommend irradiation as a means of lowering acid output in the under-60s unless associated conditions threaten life or surgery is contraindicated. In the present study four patients were below this age and two of these were under 40. Of the two youngest patients one was an alcoholic vagrant with active pulmonary tuberculosis and the other had already had a gastroenterostomy and two partial gastrectomies by the time he presented with a further jejunal ulcer. No evidence of a gastrin-secreting adenoma was found in this patient. The third patient was unfit for surgery because of a previous pneumonectomy for tuberculosis, and the fourth, a 57-year-old man, had had two gastrectomies and a vagotomy and was subsequently found to have the Zollinger-Ellison syndrome. This patient had symptomatic relief for the first four years after his radiotherapy, which was given in 1955 before the Zollinger-Ellison syndrome was recognized. Other observers (Clayman et al., 1968) of patients with gastrin-secreting adenomas have suggested that they tend to be refractory to gastric irradiation.

No patient developed nephritis after radiotherapy. Two patients had chronic renal impairment before radiotherapy and neither showed further deterioration in renal function. The poor long-term prognosis of the patients in this selected series was such that the hazard of nephritis eight to 18 years after therapy was unlikely to prove a major issue. Where possible creatinine clearance tests were carried out before and after irradiation and to date no evidence of any appreciable deterioration in renal function has been evident.

Our experience suggests that gastric irradiation provides a good chance of relief of symptoms and healing of the lesions associated with peptic ulceration and peptic oesophagitis; it does this without significant morbidity. We therefore recommend the use of radiotherapy in elderly patients with associated disease.

\section{References}

Bassler, A. (1909). Medical Times, 37, 259.

Brown, C. H., Sahba, M., and Levin, E. (1962). American fournal of Gastroenterology, 38, 278.

Bruegel, C. (1919). Münchener medizinische Wochenschrift, 64, 379.

Clayman, C. B., Palmer, W. L., and Kirsner, J. B. (1968). Gastroenterology, $55,403$.

Griffiths, J. M. T. (1972). Gerontologia Clinica, 14, 282

Hedfeld, A. (1948). Strahlentherapie, 77, 387.

Klein, H. C., and Berman, N. E. (1961). Fournal of the American Medica Association, 176, 98.

Kruglikowa, R. K., Katscher, M. L., and Aviossor, M. L. (1936). Roentgenpraxis, 8, 179.

Levin, E., et al. (1954). Fournal of the American Medical Association, 156, 1383

Levin, E., et al. (1957). Gastroenterology, 32, 42.

Ricketts, W. E., et al. (1948). Gastroenterology, 11, 789.

Thompson, P. L., et al. (1971). Quarterly fournal of Medicine, 40, 145.

\title{
Transthoracic Electrical Impedance in Cases of High-altitude Hypoxia
}

\author{
SUJOY B. ROY, \\ V. BALASUBRAMANIAN, \\ M. R. KHAN, \\ V. S. KAUSHIK, \\ S. C. MANCHANDA, \\ S. K. GUHA
}

British Medical fournal, 1974, 3, 771-775

\section{Summary}

Changes in transthoracic electrical impedance (T.E.I.) due to high-altitude hypoxia $(3,658 \mathrm{~m})$ have been measured in 20 young, healthy Indian soldiers. They were first studied at sea level $(198 \mathrm{~m})$ and then rapidly transported by air to $3,658 \mathrm{~m}$, where they were studied daily from day 1 to day 5 and then on days 8 and 10. The mean ( \pm S.D.) T.E.I. at sea level $(34.6 \pm 0.6 \Omega)$ fell sharply to $29.6 \pm 0.8 \Omega, 30 \cdot 3 \pm 0.9 \Omega$, and $30.5 \pm 1 \cdot 1 \Omega$ on days 1,2 , and 3 $(P<0.001)$ and levelled off at $31.5 \pm 0.7 \Omega$ on day 10, which was comparable to the mean value obtained in 13 persons permanently resident at high altitude $(32 \cdot 2 \pm 0 \cdot 7 \Omega)$. Five sea-level residents who had acute mountain sickness (A.M.S.) or high-altitude pulmonary oedema (H.A.P.O.) had a still lower mean value $(22 \cdot 5 \pm 1 \cdot 1 \Omega)$. One normal

All India Institute of Medical Sciences, New Delhi 16, India SUJOY B. ROY, M.B., F.R.C.P., Professor and Head of Department of Cardiology

M. R. KHAN, M.sc., Research Scholar in Biomedical Engineering V. S. KAUSHIK, M.D., D.M.(CARD.), Registrar in Cardiology

S. C. MANCHANDA, M.D., D.M.(CARD.), Lecturer in Cardiology

S. K. GUHA, M.TrCH., PH.D., Professor of Biomedical Engineering

Directorate General Armed Forces Medical Services, New Delhi V. BALASUBRAMANIAN, M.D., Research Pool Officer healthy subject who at sea level had a T.E.I. of $34 \cdot 7 \Omega$ developed H.A.P.O. when the T.E.I. fell to $21 \cdot 1 \Omega$. Ninety minutes after the administration of $80 \mathrm{mg}$ of intravenous frusemide the value increased to $35.5 \Omega$. In another subject with A.M.S. who received $40 \mathrm{mg}$ of frusemide intravenously the T.E.I. rose from 21.9 to $33.2 \Omega$.

Since the study was non-invasive the changes in impedance could not be correlated objectively with alterations in either pulmonary blood volume or pulmonary extravascular water space. In the subject, however, with X-ray evidence of H.A.P.O. and a low T.E.I. intravenous frusemide produced a marked rise in T.E.I. together with clearing of the chest $x$-ray picture within 24 hours, indicating an inverse relationship between impedance and thoracic fluid volume. It is suggested that with further objective verification in man the measurement of T.E.I. may be a potentially promising technique for the early detection of increased pulmonary fluid volume.

\section{Introduction}

In a previous study (Roy et al., 1968) the pulmonary blood volume in healthy volunteers was shown to increase by about $80 \%$ three or four days after their arrival by air at an altitude of $3,658 \mathrm{~m}$. The method used to estimate the pulmonary blood volume, however, had two inherent defects-(1) only the intravascular blood volume could be measured, and (2) since the technique was invasive repeated observations on the same subject were not feasible. Pomerantz et al. (1970) and Van De Water 